\title{
Effect of Different Dental Impression Disinfectants on the Mandibular Teeth and Dental Arch Measurements
}

\author{
Shahba'a A. Mohammed, B.D.S., M.Sc. ${ }^{1}$ Haider M. A. Ahmed, \\ B.D.S., M.Sc. ${ }^{2}$ Mohammed Nahidh, B.D.S., M.Sc. ${ }^{3}$ \\ ${ }^{1}$ Assistant Professor. Department Of Orthodontics. College of Dentistry, University of Baghdad. \\ ${ }^{2}$ Lecturer. Department of Orthodontics. College of Dentistry, University of Baghdad. \\ ${ }^{3}$ Assistant Professor. Department Of Orthodontics. College of Dentistry, University of Baghdad.
}

\begin{abstract}
Background: This study aimed to test the effect of various dental impression disinfectants on the teeth and dental arch measurements.

Materials and methods: Forty impressions for the mandibular arch were taken with alginate impression material from ten dental students each for four times. The first ten impressions (control) were washed with distilled water and poured with type IV dental stone. The other thirty impressions were immersed in Clorox (sodium hypochlorite), Biosanitizer $M$ and Zeta plus 7 (ten for each agents) for ten minutes before pouring. The mesio-distal dimension of six teeth and dental arch widths were compared between each group with the control using paired samples t-test.
\end{abstract}

Results and Conclusion: The results revealed non-significant difference between the control group and other groups, so any type of disinfectant can be used without effect on the teeth and dental arch measurements.

Keywords: Dental impression, disinfection, teeth and dental arch measurements.

\section{Introduction}

In orthodontics, cross infection of the study models through contaminated alginate impressions is a frequent event, so disinfection of the dental impression is essential for the orthodontists, assistants and laboratory technicians.

Dental impressions can be disinfected by four methods: immersion in or spraying with a disinfectant, incorporating chemicals into powder at the time of mixing ${ }^{(1-25)}$ or using self-disinfected alginate.

One of the main requirements of the disinfectant solution is the effectiveness against wide range of microorganisms including bacteria, viruses and fungi at the same time it should not affect the physical and mechanical properties of the impression material and should be non-toxic to human tissues also easy to use with reasonable price ${ }^{(26)}$.

The literature is rich with the disinfectant materials used to disinfect the dental impressions like aldehydes, chlorine compound, chlorhexidine, iodine compound and sodium fluoride. The effects of these materials on the physical and mechanical properties of alginate in addition to testing their microbial activity have been evaluated in pervious researches ${ }^{(2-25)}$.

In orthodontics, Jones et al. ${ }^{(27,28)}$ were the first who study the dimensional stability of disinfected alginate impression concentrating on dental arch width and length. The present study aimed to evaluate the effect of various dental impressions disinfectants on the mesio-distal teeth measurements and dental arch widths from orthodontic point of view.

Sample

\section{Materials And Methods}

Ten students (five males and five females) from the College of Dentistry, University of Baghdad participated in this study. All have class I occlusion with well-aligned or with mild spacing or crowding.

Impression for the mandibular arch was taken with alginate impression material (Kromopan, Lascod Company, Italy) for each student four times successively according to the manufacturer's instructions. The impressions were then washed with distilled water and divided according to the disinfectant used. Each ten impressions were immersed in the specific disinfectant for ten minutes before pouring.

\section{Disinfectant solutions}

1. Clorox: it is manufactured by National Cleaning Products Company, KSA. It composed of $5.25 \%$ sodium hypochlorite. 
2. Biosanitizer M: it is manufactured by SaniSwiss Company, Switzerland. It is supplied as a powder to be mixed with water. It composed of powder-based on monopersulfate compounds, surfactants, chelating and acidifying agents. Active oxygen released after dilution of powder in $\mathrm{H}_{2} \mathrm{O}$.

3. Zeta 7 solution: it is manufactured by Zhermack Company, Italy. It composed of ethanolamine, acetic acid, $\mathrm{N}, \mathrm{N}$-didecyl-N, N-dimethylammonium chloride, butane-1, 4-diol.

\section{Methods}

Preparation of the disinfectants, disinfection of the impressions and measurements

Clorox was diluted with distilled water at a ratio of 1 part of bleach to 10 parts of water to make 1:10 ratio. Biosanitizer $\mathrm{M}$ was prepared by mixing $60 \mathrm{~g}$ of powder with $3 \mathrm{~L}$ of water while Zeta 7 was used at $1 \%$ after dilution with distilled water.

The impressions were washed and immersed in the specific disinfectant for 10 minutes according to the manufacturers' instructions then washed and poured with type IV dental stone (Elite ${ }^{\circledR}$ stone, Zhermack, Italy). After setting, the casts were obtained and photographed in the same method of Hasan ${ }^{(29)}$ and Ahmed ${ }^{(30)}$.

\section{Teeth and dental arch measurements}

The mesio-distal widths of the right central incisor, canine and $2^{\text {nd }}$ premolar and left lateral incisor, $1^{\text {st }}$ premolar and $1^{\text {st }}$ molar were measured occlusally (incisally) from the contact points ${ }^{(31)}$. The arch widths at the canine, $1^{\text {st }}$ premolars and $1^{\text {st }}$ molars were measured at the level of cusp tips (buccal cusp tip of $1^{\text {st }}$ premolar and mesio-buccal cusp tips for $1^{\text {st }}$ molar) ${ }^{(30,32)}$ using AutoCAD program 2015.

\section{Statistical analyses}

The collected data were analyzed using SPSS program version 21. The descriptive statistics included the means and standard deviations while the inferential statistics included the paired samples t-test to compare the measurements between the control group and other groups. P-value above 0.05 indicated non-significant difference.

\section{Results}

Table 1 showed the descriptive statistics of the measured variables in mm. Generally, the mean values of the variables were approximate among the groups. Paired samples t-test revealed non-significant difference when the studied groups compared with the control group separately.

Table 1: Descriptive statistics of the measured variables in each group

\begin{tabular}{|c|c|c|c|c|c|c|c|c|}
\hline $\begin{array}{c}\text { Measurement } \\
(\mathrm{mm} .)\end{array}$ & \multicolumn{2}{|c|}{ Distilled water } & \multicolumn{2}{c|}{ Clorox } & \multicolumn{2}{c|}{ Biosanitizer M } & \multicolumn{2}{c|}{ Zeta 7 } \\
\cline { 2 - 9 } & Mean & S.D. & Mean & S.D. & Mean & S.D. & Mean & S.D. \\
\hline R1 & 6.071 & 0.385 & 6.030 & 0.415 & 6.036 & 0.477 & 6.029 & 0.351 \\
\hline L2 & 6.668 & 0.452 & 6.540 & 0.399 & 6.624 & 0.486 & 6.624 & 0.366 \\
\hline R3 & 7.600 & 0.454 & 7.501 & 0.415 & 7.488 & 0.472 & 7.532 & 0.375 \\
\hline L4 & 7.507 & 0.443 & 7.463 & 0.673 & 7.463 & 0.527 & 7.210 & 1.068 \\
\hline R5 & 8.031 & 0.695 & 7.782 & 0.788 & 7.913 & 0.626 & 8.038 & 0.493 \\
\hline L6 & 11.585 & 0.660 & 11.425 & 0.541 & 11.642 & 0.720 & 11.441 & 0.372 \\
\hline ICD & 30.768 & 2.129 & 30.548 & 2.297 & 30.475 & 2.273 & 30.588 & 2.035 \\
\hline IPD & 40.521 & 3.837 & 40.518 & 3.865 & 40.254 & 3.880 & 40.386 & 3.749 \\
\hline IMD & 51.695 & 3.500 & 51.507 & 4.046 & 51.435 & 4.256 & 51.650 & 3.208 \\
\hline
\end{tabular}

Table 2: Comparing the measurements between the control group and other groups

\begin{tabular}{|c|c|c|c|c|c|c|c|c|c|}
\hline \multirow{2}{*}{$\begin{array}{c}\text { Measurement } \\
\text { (mm.) }\end{array}$} & \multicolumn{2}{|c|}{ Distilled water vs. Clorox } & \multicolumn{2}{c|}{ Distilled water vs. Biosanitizer M } & \multicolumn{3}{c|}{ Distilled water vs. Zeta 7 } \\
\cline { 2 - 10 } & $\begin{array}{c}\text { Mean } \\
\text { difference }\end{array}$ & t-test & p-value & $\begin{array}{c}\text { Mean } \\
\text { difference }\end{array}$ & t-test & p-value & $\begin{array}{c}\text { Mean } \\
\text { difference }\end{array}$ & t-test & p-value \\
\hline R1 & 0.041 & 0.623 & 0.549 & 0.035 & 0.360 & 0.727 & 0.042 & 0.974 & 0.356 \\
\hline L2 & 0.128 & 1.861 & 0.096 & 0.044 & 0.766 & 0.463 & 0.044 & 0.518 & 0.617 \\
\hline R3 & 0.099 & 1.246 & 0.244 & 0.112 & 0.991 & 0.348 & 0.068 & 0.693 & 0.506 \\
\hline L4 & 0.044 & 0.327 & 0.751 & 0.044 & 0.393 & 0.703 & 0.297 & 0.801 & 0.444 \\
\hline R5 & 0.249 & 1.634 & 0.137 & 0.118 & 0.871 & 0.407 & -0.007 & -0.065 & 0.950 \\
\hline L6 & 0.160 & 1.218 & 0.254 & -0.057 & -0.470 & 0.649 & 0.144 & 0.918 & 0.382 \\
\hline ICD & 0.220 & 0.798 & 0.446 & 0.293 & 1.032 & 0.329 & 0.180 & 1.067 & 0.314 \\
\hline IPD & 0.003 & 0.011 & 0.991 & 0.267 & 0.525 & 0.612 & 0.135 & 1.174 & 0.271 \\
\hline IMD & 0.188 & 0.578 & 0.577 & 0.260 & 0.555 & 0.593 & 0.045 & 0.288 & 0.825 \\
\hline
\end{tabular}

$\mathrm{R} 1=$ right central incisor, $\mathrm{L} 2=$ left lateral incisor, $\mathrm{R} 3=$ right canine, $\mathrm{L} 4=$ left $1^{\text {st }}$ premolar, $\mathrm{R} 5=$ right $2^{\text {nd }}$ premolar, L6= left $1^{\text {st }}$ molar, ICD $=$ inter-canine distance, $\mathrm{IPD}=$ inter- $1^{\text {st }}$ premolar distance, $\mathrm{IMD}=$ inter- $1^{\mathrm{st}}$ molar distance 


\section{Discussion}

Infection control in the dental practice is far imperative as the microorganisms can be transmitted easily by saliva and blood to the dental staff.

Dental casts are one of the vital diagnostic aids utilized by the orthodontists to visualize the teeth and occlusion in three dimensions, select orthodontic bands and determine the treatment plan after space analysis ${ }^{(33)}$. Dental impressions that were obtained from the patients harbored many types of microorganisms hosted inside the patient's mouth. Pouring such impression may transfer such microorganisms to the study casts so the orthodontists, assistants and technicians are in danger.

Generally, the specialists in fixed and removable dental prostheses and dental materials studied the microbial activities and the effects of various disinfectants on the properties of the impression materials ${ }^{(2-25)}$. Orthodontists deal with the dimensional changes that may be associated with disinfected alginate impression as the poured casts will be used in construction of removable orthodontic appliances and space analysis.

In this study, ten students had normal occlusion with well-aligned arches or with mild spacing or crowding were agreed to participate. Four impressions have been taken by one of the authors for the lower arch. The first one just washed with distilled water and poured with type IV stone, while the other three impressions were immersed in three different disinfectants (Clorox, Bio-sanitizer M and Zeta 7) for ten minutes then washed with distilled water and poured as the control group under the manufacturer's instructions. Mesio-distal dimensions of six teeth (three in the right and three in the left side) and dental arch widths at the canine, $1^{\text {st }}$ premolar and molar area were measured.

Sodium hypochlorite was used previously in the researches and had strong anti-microbial effects. In 2008, the CDC has advised that household bleach of 1:10 dilution should be used for disinfection of hydrocolloid impressions ${ }^{(34)}$. Correia-Sousa et al. ${ }^{(35)}$ found that washing alginate impression with tap water reduced the microbial load significantly by $48.5 \%$, while sodium hypochlorite decreased the adherence of microorganisms by $99.99 \%$. Immersion alginate impressions in sodium hypochlorite solution led to absorbing water due to the difference in the osmotic pressure between the disinfection solution and the alginate impression (36). The dimensional stability of an alginate impression after immersion in sodium hypochlorite solution varied according to kinds and brands but small dimensional changes of the alginate impression had been reported in sodium hypochlorite solution and this in accordance with the present findings.

Bio-sanitizer $\mathrm{M}$ and Zeta 7 were used for the fist time up to authors' knowledge. According to the manufacturers, they had wide range anti-microbial activity against many types of bacteria, virus and fungi in addition to their negligible effect of the dimensional changes. The outcome of the present study proved statistically non-significant differences in the measured variables between the control group and the studied groups meaning that any type can be used for disinfection safely; this comes in agreement with Jones et al. ${ }^{(27,28)}$ who found the same findings.

\section{Conclusions}

Disinfection of the dental impressions is vital compulsory measure to prevent the transmission of microorganisms and diseases. Any of the tested disinfectants can be used safely in impression disinfection prior to pouring with dental stone without compromising the teeth and dental arch measurements.

\section{References}

[1]. ADA council on scientific affairs and ADA council on dental practice. Infection control recommendations for the dental office and dental laboratory. JADA 1996; 127(5): 672-80

[2]. Jagger DC, Al Jabra O, Harrison A, Vowles RW, McNally L. The effect of a range of disinfectants on the dimensional accuracy of some impression materials. Eur J Prosthodont Restor Dent 2004; 12(4):154-60.

[3]. Hussain SM, Tredwin CJ, Nesbit M, Moles DR. The effect of disinfection on irreversible hydrocolloid and type III gypsum casts. Eur J Prosthodont Restor Dent 2006; 14(2): 50-4.

[4]. Hiraguchi H, Nakagawa H, Kaketani M, Hirose H, Nishiyama M. Effects of disinfection of combined agar/alginate impressions on the dimensional accuracy of stone casts. Dent Mater J 2007; 26(3): 457-62.

[5]. Ghahramanloo A, Sadeghian A, Sohrabi K, Bidi A. A microbiologic investigation following the disinfection of irreversible hydrocolloid materials using the spray method. J Calif Dent Assoc 2009; 37(7): 471-7.

[6]. Rweyendela IH, Patel M, Owen CP. Disinfection of irreversible hydrocolloid impression material with chlorinated compounds. SADJ 2009; 64(5): 208, 210-2.

[7]. Semensato AP, Crosariol SK, Marchini L. Evaluation of the antimicrobial activity and dimensional alterations of alginate impression disinfectants. Eur J Prosthodont Restor Dent 2009; 17(3):121-5.

[8]. Shambhu HS, Gujjari AK. A study on the effect on surface detail reproduction of alginate impressions disinfected with sodium hypochlorite and ultraviolet light - An In Vitro study. J Indian Prosthodont Soc 2010; 10(1): 41-7.

[9]. Hiraguchi H, Kaketani M, Hirose H, Yoneyama T. The influence of storing alginate impressions sprayed with disinfectant on dimensional accuracy and deformation of maxillary edentulous stone models. Dent Mater J 2010; 29(3): 309-15.

[10]. Hamedi Rad F, Ghaffari T, Safavi SH. In vitro evaluation of dimensional stability of alginate impressions after disinfection by spray and immersion methods. J Dent Res Dent Clin Dent Prospects 2010; 4(4):130-5.

[11]. Jani SJ, Mohammed NH, Abdulrasool M. Efficacy of various chlorhexidine disinfecting agents on the reduction of bacteria and dimensional stability of alginate impression material. Magazine Al-Kufa Uni Biol 2010; 2(1): 144-52. 
[12]. Rentzia A, Coleman DC, O'Donnell MJ, Dowling AH, O'Sullivan M. Disinfection procedures: their efficacy and effect on dimensional accuracy and surface quality of an irreversible hydrocolloid impression material. J Dent 2011; 39(2):133-40.

[13]. Samra RK, Bhide SV. Efficacy of different disinfectant systems on alginate and addition silicone impression materials of Indian and international origin: a comparative evaluation. J Indian Prosthodont Soc 2010; 10(3):182-9.

[14]. Al-Harby HA, Ibrahim IKh. The effect of certain disinfectant agents on alginate impression material. J Bagh Coll Dentistry 2011; 23(2): 13-6.

[15]. Hiraguchi H, Kaketani M, Hirose H, Yoneyama T. Effect of immersion disinfection of alginate impressions in sodium hypochlorite solution on the dimensional changes of stone models. Dent Mater J 2012; 31(2): 280-6.

[16]. Haralur SB, Al-Dowah OS, Gana NS, Al-Hytham A. Effect of alginate chemical disinfection on bacterial count over gypsum cast. J Adv Prosthodont 2012; 4(2): 84-8.

[17]. Badrian H, Ghasemi E, Khalighinejad N, Hosseini N. The effect of three different disinfection materials on alginate impression by spray method. ISRN Dent 2012; 2012: 695151.

[18]. Alwahab Z. Comparison of antimicrobial activities and compressive strength of alginate impression materials following disinfection procedure. J Contemp Dent Pract 2012; 13(4): 431-5.

[19]. Guiraldo RD, Borsato TT, Berger SB, Lopes MB, Gonini-Jr A, Sinhoreti MA. Surface detail reproduction and dimensional accuracy of stone models: influence of disinfectant solutions and alginate impression materials. Braz Dent J 2012; 23(4): 417-21.

[20]. Al-Dulaimi SF, Al-Wahab ZN. The effect of disinfectants on the surface quality of irreversible hydrocolloid impression material and gypsum cast. Iraqi National J Nursing Specialties 2012; 25(1): 95-100.

[21]. Amalan A, Ginjupalli K, Upadhya N. Evaluation of properties of irreversible hydrocolloid impression materials mixed with disinfectant liquids. Dent Res J (Isfahan) 2013; 10(1): 65-73.

[22]. Al-Khafagy MT, Al-Yasiri IK, Hamed SJ. Disinfection of alginate and silicon impressions by using UV and blue light (In Vivo study). J Kufa Nursing Sci 2013; 3(2): 184-91.

[23]. Hussian AM, Jassim RK. Effect of sodium fluoride addition as a disinfectant on some properties of alginate impression material. J Bagh Coll Dentistry 2015; 27(1): 70-6.

[24]. Demajo JK, Cassar V, Farrugia C, Millan-Sango D, Sammut C, Valdramidis V, Camilleri J. Effectiveness of disinfectants on antimicrobial and physical properties of dental impression materials. Int J Prosthodont 2016; 29(1): 63-7.

[25]. Iwasaki Y, Hiraguchi H, Iwasaki E, Yoneyama T. Effects of immersion disinfection of agar-alginate combined impressions on the surface properties of stone casts. Dent Mater J 2016; 35(1): 45-50.

[26]. Council on dental therapeutics, council on prosthetic service and dental laboratory relations. Guidelines for infection control in the dental office and the commercial dental laboratory. JADA 1985; 110(6): 969-72.

[27]. Jones ML, Newcombe RG, Barry G, Bellis H, Bottomley J. A Reflex plotter investigation into three-dimensional stability of alginate impressions following disinfection by varying regimes employing 2.2 percent glutaraldehyde. Br J Orthod 1988; 15(3):185-92.

[28]. Jones ML, Newcombe RG, Bellis H, Bottomley J. The dimensional stability of self-disinfecting alginate impressions compared to various immersion regimes. Angle Orthod 1990; 60(2): 123-8.

[29]. Hasan ZS. The effect of nutritional status on dental health, salivary physicochemical characteristics and odontometric measurements among five years old kindergarten children and fifteen years old students. Ph.D. thesis, Department of Pedodontics and Preventive Dentistry, College of Dentistry, University of Baghdad, 2010.

[30]. Ahmed HMA, Ali FA. Dental arches dimensions, forms and the relation to facial types in a sample of Iraqi adults with skeletal and dental class I normal occlusion. J Bagh Coll Dentistry 2012; 24(sp. Issue 1): 99-107.

[31]. Hunter WS, Priest WR. Errors and discrepancies in measurement of tooth size. J Dent Res 1960; 39(2): 405-14.

[32]. Mohammed IS. Maxillary arch dimensions. A cross sectional study between 9-17 years. A master thesis, Department of POP, College of Dentistry, University of Baghdad, 1993.

[33]. Mitchell L. Introduction to orthodontics. $4^{\text {th }}$ ed. Oxford: Oxford university press; 2013.

[34]. Rutala WA, Weber DJ. Healthcare Infection Control Practices Advisory Committee. (HICPAC). Guideline for disinfection and sterilization in healthcare facilities, 2008. Atlanta: Centers for Disease Control and Prevention (CDC); 2008. p. 20-1, 39-42, 48-9, 88-9, 104-5.

[35]. Correia-Sousa J, Tabaio AM, Silva A, Pereira T, Sampaio-Maia B, Vasconcelos M. The effect of water and sodium hypochlorite disinfection on alginate impressions. Rev Port Estomatol Med Dent Cir Maxilofac 2013; 54(1): 8-12.

[36]. Saito S, Ichimaru T, Araki Y. Factors affecting dimensional instability of alginate impressions during immersion in the fixing and disinfectant solution. Dent Mater J 1998; 17(4): 294-300. 